\title{
ARMAZENAMENTO DE SEMENTES DE CAFEEIRO: AMBIENTES E MÉTODOS DE SECAGEM $^{1}$
}

\author{
ANTÔNIO RODRIGUES VIEIRA², JOÃOALMIROLIVEIRA³ ${ }^{3}$ RENATOMENDES GUIMARÃES ${ }^{4}$, CARLOS EDUARDO PEREIRA $^{5}$, \\ FERNANDAELISADE CARVALHO ${ }^{6}$
}

\begin{abstract}
RESUMO - Sementes de cafeeiro perdem rapidamente a viabilidade durante o armazenamento, o que torna um grande problema a manutenção da qualidade fisiológica destas, por parte dos produtores, até o momento adequado de semeadura. Nessa pesquisa, investigou-se o desempenho de sementes de cafeeiro (Coffea arabica L.) secadas por diferentes métodos e armazenadas em diferentes condições de ambiente. Para tanto foram utilizadas sementes de cafeeiro, cultivar Rubi, colhidas na safra 2001/2002, na Universidade Federal de Lavras (UFLA). Após a degomagem dos frutos, uma parte das sementes não recebeu secagem, permanecendo com 47,5\% de teor de água e a outra parte foi fracionada em duas subamostras e secadas até atingir $12 \%$. As sementes foram submetidas à secagem lenta em ambiente aberto $\left(20^{\circ} \mathrm{C}\right.$ e $60 \%$ de umidade relativa do ar (UR)) ou à secagem rápida em estufa de circulação forçada de ar a $35^{\circ} \mathrm{C}$. Em seguida, as sementes foram acondicionadas em embalagens herméticas e armazenadas na UFLA, por um período de nove meses, em dois ambientes: armazém convencional e em câmara fria e seca, a $10^{\circ} \mathrm{C}$ e $50 \%$ de UR. Antes do armazenamento e a cada três meses, as sementes foram avaliadas pelas seguintes determinações: teor de água, teste de germinação, emergência de plântulas, índice de velocidade de emergência e teste de tetrazólio. Pode-se concluir que, a secagem rápida prejudica o vigor e a viabilidade das sementes de cafeeiro, independentemente do local de armazenamento. Em condições de câmara fria é possível armazenar por nove meses sementes sem secagem ou secadas lentamente. Independentemente do tipo de secagem, o vigor das sementes é afetado no armazenamento em condições de armazém convencional.
\end{abstract}

Termos para indexação: Coffea arabica, germinação, viabilidade.

\section{STORAGE OFTHECOFFEE SEEDS: DRYING METHODS ANDENVIRONMENTS}

\begin{abstract}
The loss of seed viability, what makes it difficult to keep the high physiological quality, is one the greatest problems faced by the coffee seed producers during seed storage. Thus, the performance of the coffee seeds (Coffea arabica L. cv. Rubi) during storage harvested in 2001/2002, at Federal University of Lavras-Brazil (UFLA), was investigated. After cleaning seeds were kept at $47,5 \%$ of water content (WC), fast (forced air chamber at $35^{\circ} \mathrm{C}$ ) and slow (open environment with $20^{\circ} \mathrm{C}$ and $60 \%$ of relative humidity (RH)) dried until reaching $12 \%$. The seeds were packed in hermetic bags and stored for 9 months at two environments: regular, with monitored temperature and $\mathrm{RH}$, and in dry cold chamber at $10^{\circ} \mathrm{C}$ and $50 \%$ of $\mathrm{RH}$. Before storage and every three months seed quality was evaluated by the germination test, seedlings emergency, emergency speed index and tetrazolium test. Fast drying decreases the vigor of seeds independent from where they dry. In cold chamber it is possible to store regular seeds or slowly dried seeds for up to nine months. In a regular warehouse environment the vigor is affected independently from the way they are dried.
\end{abstract}

Index terms: Coffea arabica, germination, viability.

\footnotetext{
${ }^{1}$ Submetido em 28/11/2005. Aceito para publicação em 15/11/2006.

${ }^{2}$ Eng $^{\circ}$ Agrônomo, Dr., Pesquisador, EPAMIG/CTSM, Cx. Postal 176, 37200000, Lavras-MG. arvieira@ufla.br

${ }^{3}$ Biólogo, Dr., Professor, UFLA, Cx. Postal 3037, 37200-000, Lavras-MG. jalmir@ufla.br
}

\footnotetext{
${ }^{4}$ Eng ${ }^{\circ}$ Agrônomo, Dr., Professor, UFLA, Cx. Postal 3037, 37200-000, Lavras-MG. renatomg@ufla.br

5-Pós-Graduando, UFLA, Cx. Postal 3037, 37200-000, Lavras-MG, cepereira@bol.com.br

${ }^{6}$ Graduanda, UFLA, Cx. Postal 3037, 37200-000, Lavras-MG
} 


\section{INTRODUÇÃO}

A dificuldade relativa à germinação de sementes de cafeeiro, armazenadas, tem sido uma das maiores preocupações dos produtores das sementes, uma vez que estas não conservam seu poder germinativo em valores satisfatórios por períodos superiores a seis meses após a colheita. Dessa maneira, a necessidade de utilização de sementes novas para a formação de mudas, condiciona a implantação da lavoura em épocas que nem sempre são as mais apropriadas para o plantio. Entretanto, a possibilidade de obtenção de sementes de alta qualidade em qualquer época do ano, por meio do armazenamento destas, oferece ao produtor a oportunidade de programar a instalação de sua lavoura na melhor época para sua região, conseqüentemente, com formação de lavouras mais precoces e produtivas. Outro aspecto relevante que justifica os esforços para aumentar o período de conservação das sementes de cafeeiro refere-se à preservação do patrimônio genético em bancos de germoplasmas de maneira econômica e segura.

A viabilidade das sementes, no armazenamento, pode ser influenciada pela espécie, variedade, qualidade inicial, umidade e temperatura das sementes, umidade relativa e temperatura de armazenagem, fungos e insetos, tipo de embalagem e duração do período de armazenamento (Roberts, 1972; Minor e Paschal, 1982; Popinigis, 1985; Tekrone et al. 1987; Carvalho e Nakagawa, 2000).

Devido à curta viabilidade apresentada pelas sementes de cafeeiro, King e Roberts (1979) inicialmente incluíram estas no grupo das recalcitrantes, ou seja, perdem mais rapidamente a viabilidade ao serem armazenadas com o grau de umidade reduzido e em ambientes com temperaturas relativamente baixas. Posteriormente, Ellis et al. (1990) indicaram uma categoria intermediária para as sementes de cafeeiro, observando que sementes de quatro cultivares de Coffea arabica não tiveram a germinação diminuídas ao serem secadas até cerca de $10 \%$ de umidade, mas foram prejudicadas pelo armazenamento às temperaturas de $0^{\circ} \mathrm{C} \mathrm{e} \mathrm{-}$ $20^{\circ} \mathrm{C}$, comportamento característico da categoria intermediária. Sementes dessa categoria podem resistir à secagem até certo nível, mas têm sua armazenabilidade reduzida.

Muitos trabalhos envolvendo técnicas de armazenamento, têm sido desenvolvidos para manter a germinação das sementes de cafeeiro. Trabalhando com sementes de Coffea arabica, Coffea canephora e Coffea stenophyela, Couturon (1980), observou que as sementes armazenadas em condições ambientais $\left(25^{\circ} \mathrm{C}\right)$, teor de água de $15 \%$, perdiam o poder germinativo em dois meses e, no entanto, quando as sementes eram submetidas à temperatura de $19^{\circ} \mathrm{C}$, o período de conservação aumentava para 26 meses para a Coffea arabica e 11 meses para a Coffea canephora, com o poder germinativo mantido em 90 e em 80-90\%, respectivamente. Andreoli (1992) verificou que a qualidade fisiológica das sementes de Coffea canephora foi mais preservada quando armazenada com umidade de $35 \%$ em sacos de polietileno, independentemente do processo de secagem.

Em trabalho desenvolvido por Valio (1976), sob temperatura ambiente, a viabilidade de sementes de café armazenadas com teor de água de $13 \%$ foi completamente perdida após oito meses, embora somente uma pequena redução tenha sido detectada após 12 meses de armazenamento em sementes com teor de água em torno de 40\%. Entretanto, Vossen (1979) concluiu ser mais indicado o armazenamento de sementes de café a $15^{\circ} \mathrm{C}$ e teor de água de $41 \%$ do que a $15^{\circ} \mathrm{C}$ teor de água de $11 \%$.

Sementes de cafeeiro secadas até umidade de $35 \%$ e acondicionadas em embalagem de polietileno mantiveram germinação de $70 \%$ após oito meses de armazenamento, enquanto aquelas com umidade de 15 e $25 \%$, na mesma embalagem, tiveram redução na germinação e no vigor a partir de quatro meses, ficando o vigor próximo de zero (Vasconcelos et al., 1992). Já Miglioranza (1982) e Miranda e Valias (1984) obtiveram resultados satisfatórios com armazenamento por nove meses em condições herméticas e com graus de umidade mais baixos, entre 8 e $10 \%$ e $16 \%$, respectivamente.

São vários os esforços de pesquisadores e produtores, visando caracterizar as melhores condições de preservação da qualidade fisiológica das sementes de cafeeiro por períodos mais longos. Diante desses fatos, o presente trabalho teve como objetivo avaliar o desempenho de sementes de Coffea arabica secadas por diferentes métodos e armazenadas em diferentes condições de ambiente.

\section{MATERIALE MÉTODOS}

O presente trabalho foi desenvolvido no Laboratório de Análise de Sementes do Departamento de Agricultura, na Universidade Federal de Lavras-MG (UFLA), utilizando sementes de cafeeiro da espécie Coffea arabica, cultivar Rubi, produzidas na safra 2001/2002 pela UFLA.

Após a degomagem, as sementes foram divididas em três tratamentos. O primeiro, com $47,5 \%$ de umidade, foi 
constituído pelas sementes não submetidas à secagem. Os outros dois, foram formados pelas sementes secadas até atingirem teor de água de $12 \%$, sendo um obtido por meio de secagem lenta em ambiente aberto (aproximadamente $20^{\circ} \mathrm{C}$ e $60 \%$ de UR) e o outro por secagem rápida em estufa de circulação forçada de ar a $35^{\circ} \mathrm{C}$. Posteriormente as sementes foram acondicionadas em embalagens herméticas (Carvalho, 2001) e armazenadas por um período de nove meses (junho/ 2002 a março/2003). Para tanto, parte das sementes de cada tipo do fator secagem foi armazenada na UFLA em condições de armazém convencional (sem controle de temperatura e UR) e outra parte em câmara fria e seca $\left(10^{\circ} \mathrm{C}\right.$ e $50 \%$ de UR).

As sementes submetidas ao ambiente de armazém convencional tiveram a temperatura e a umidade relativa do ar monitoradas por meio de termohigrógrafo cujos resultados encontram-se nas Figuras 1 e 2. Nas condições de câmara fria e seca, o ambiente foi ajustado para manter temperatura próxima a $10^{\circ} \mathrm{C}$ e umidade relativa do ar de $50 \%$.

As sementes foram submetidas a avaliações realizadas antes (sementes não armazenadas) e após três, seis e nove meses de armazenamento, por meio das seguintes determinações:

Teor de água: determinado pelo método da estufa a $105 \pm 3^{\circ} \mathrm{C}$ durante 24 horas, utilizando duas repetições, conforme as Regras para Análise de Sementes (Brasil, 1992);

Teste de germinação: realizado utilizando quatro repetições de 50 sementes. O endocarpo das sementes foi removido antes da semeadura, a qual foi realizada utilizandose rolo de papel, umedecido com água na quantidade de 2,5 vezes o peso do papel. Os rolos foram mantidos à $30^{\circ} \mathrm{C} \mathrm{e}$ fotoperíodo de 12 horas e as avaliações foram realizadas ao 15 e 30 dias após semeadura (Brasil, 1992). Foram consideradas plântulas normais àquelas que apresentavam hipocótilo sem danos, raiz primária e raízes secundárias ou pêlos radiculares, e a metade do endosperma não danificado.

Emergência de plântulas: foram utilizadas quatro repetições de 50 sementes, as quais foram semeadas em bandeja com substrato areia+solo (2:1), a uma profundidade de $3 \mathrm{~cm}$. As bandejas foram mantidas à $30^{\circ} \mathrm{C}$, fotoperíodo de 12 horas e com irrigação periódica. A emergência foi determinada com contagem das plântulas emergidas aos 60 dias após semeadura. Foram consideradas emergidas as plântulas que apresentavam os cotilédones acima do substrato.

Índice de velocidade de emergência: conduzido conjuntamente com o teste de emergência. A velocidade de emergência foi determinada anotando-se diariamente o número de plântulas emergidas com os cotilédones acima do

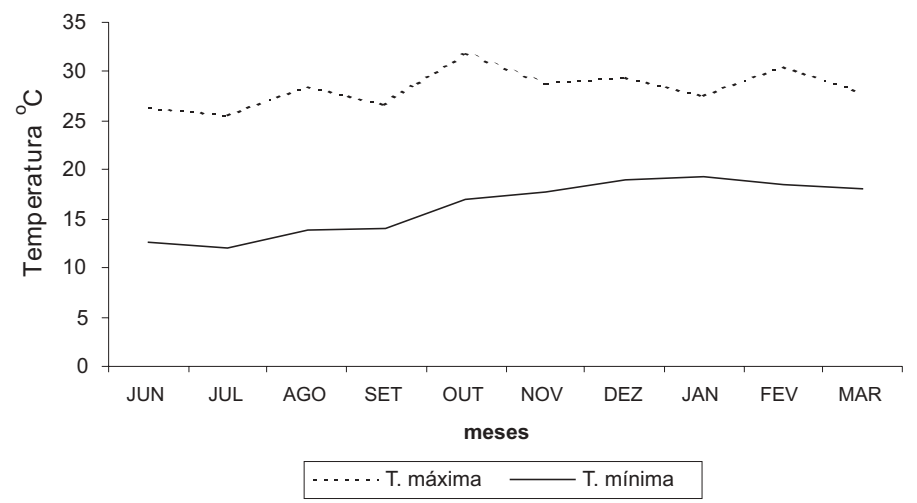

FIGURA 1. Temperaturas máximas e mínimas $\left({ }^{\circ} \mathrm{C}\right)$ referentes ao período de junho de 2002 a março de 2003 . UFLA, Lavras - MG.

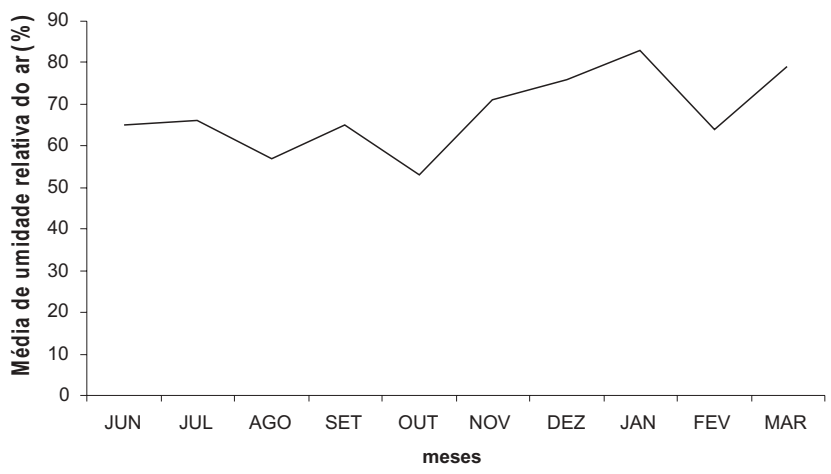

FIGURA 2. Média de umidade relativa do ar (\%) referente ao período de junho de 2002 a março de 2003. UFLA, Lavras - MG.

substrato, até a completa estabilização do estande. O índice de velocidade de emergência foi calculado segundo Maguire (1962).

Teste de tetrazólio: efetuado utilizando quatro repetições de 50 sementes, as quais foram embebidas por 52 horas a $25^{\circ} \mathrm{C}$ em câmara tipo BOD. Decorrido esse período, foi realizado o corte longitudinal sobre o eixo embrionário das sementes, de modo a expor o embrião. Posteriormente foram transferidas para copos plásticos contendo solução a $0,25 \%$ de sal de tetrazólio (cloreto 2,3,5 trifenil tetrazólio), onde permaneceram por um período de 16 horas a $25^{\circ} \mathrm{C}$, em ambiente escuro. Após este período as sementes foram lavadas e avaliadas individualmente com auxílio de microscópio esterioscópico e classificadas em viáveis e não viáveis.

O delineamento utilizado foi o inteiramente casualizado, em esquema fatorial $2 \times 3 \times 4$ (dois ambientes de armazenamento, três tipos de secagem e quatro épocas de avaliação), com quatro repetições. Para as variáveis que apresentaram efeito significativo pelo teste $\mathrm{F}$ foi utilizado o 
teste de Tukey a 5\% de probabilidade e análise de regressão.

\section{RESULTADOS E DISCUSSÃO}

Foram observadas, pelos resultados encontrados para avaliação do teor de água, que as umidades das sementes armazenadas, praticamente mantiveram-se inalteradas ao longo dos nove meses, tanto para aquelas com alta, quanto para as com baixa umidade inicial, em quaisquer das duas condições de armazenamento (câmara fria ou armazém convencional).

Pelos resultados do teste de germinação observa-se que armazenadas em câmara fria, as sementes que não foram secadas e aquelas que foram submetidas à secagem lenta tiveram resultados semelhantes em relação à conservação do poder germinativo, com menor redução linear na germinação até os nove meses de armazenamento, em relação aos demais tratamentos (Figura 3). Tais resultados concordam em parte com aqueles encontrados por Gentil et al. (2001), os quais trabalhando com Coffea arabica L., verificaram que as reduções do grau de umidade até $10 \%$ e da temperatura até $10^{\circ} \mathrm{C}$ são favoráveis à manutenção da qualidade fisiológica das sementes Do mesmo modo, as sementes não secadas e armazenadas em armazém convencional tiveram seu poder germinativo reduzido no mesmo período. Embora esta redução tenha sido maior que as ocorridas nas citadas anteriormente, estas sementes também permaneceram com a germinação dentro dos padrões mínimos $(70 \%)$ exigidos pelo Instituto Mineiro de Agropecuária (IMA, 2000), até aproximadamente o quinto mês de armazenamento. Para os demais tratamentos estudados a preservação da germinação das sementes após o terceiro mês de armazenamento não foi satisfatória, já que as sementes tiveram uma acentuada redução da germinação durante o armazenamento.

Resultados semelhantes foram verificados por meio do teste de tetrazólio (Figura 4), confirmando, dessa maneira, os resultados encontrados no teste de germinação.

Na comparação da qualidade fisiológica por meio dos testes de emergência de plântulas (Figura 5) e do índice de velocidade de emergência (Figura 6), para a fonte de variação épocas, verifica-se que houve um comportamento semelhante de resultados entre estas variáveis respostas. De maneira geral as sementes, ao longo do armazenamento tiveram uma redução linear destes parâmetros estudados, independentemente do local de armazenamento bem como do tratamento de secagem utilizado.

Pelos resultados de emergência de plântulas, no estudo

$$
\begin{array}{ll}
\mathrm{y}_{\mathrm{A}}=99,425-4,025 \mathrm{x} & \mathrm{R}^{2}=89,2 \% \\
\mathrm{y}_{\mathrm{B}}=98,475-6,092 \mathrm{x} & \mathrm{R}^{2}=90,4 \% \\
\mathrm{y}_{\mathrm{C}}=98,650-9,783 \mathrm{x} & \mathrm{R}^{2}=84,1 \% \\
\mathrm{y}_{\mathrm{D}}=98,050-9,650 \mathrm{x} & \mathrm{R}^{2}=89,9 \% \\
\mathrm{y}_{\mathrm{E}}=96,200-3,933 \mathrm{x} & \mathrm{R}^{2}=91,5 \% \\
\mathrm{y}_{\mathrm{F}}=98,250-15,667 \mathrm{x}+0,444 \mathrm{x}^{2} & \mathrm{R}^{2}=92,4 \%
\end{array}
$$

(A) Sem secagem; câmara fria

(B) Sem secagem; convencional

(C) Secagem rápida; câmara fria

(D) Secagem rápida; convencional

(E) Secagem lenta; câmara fria

(F) Secagem lenta; convencional
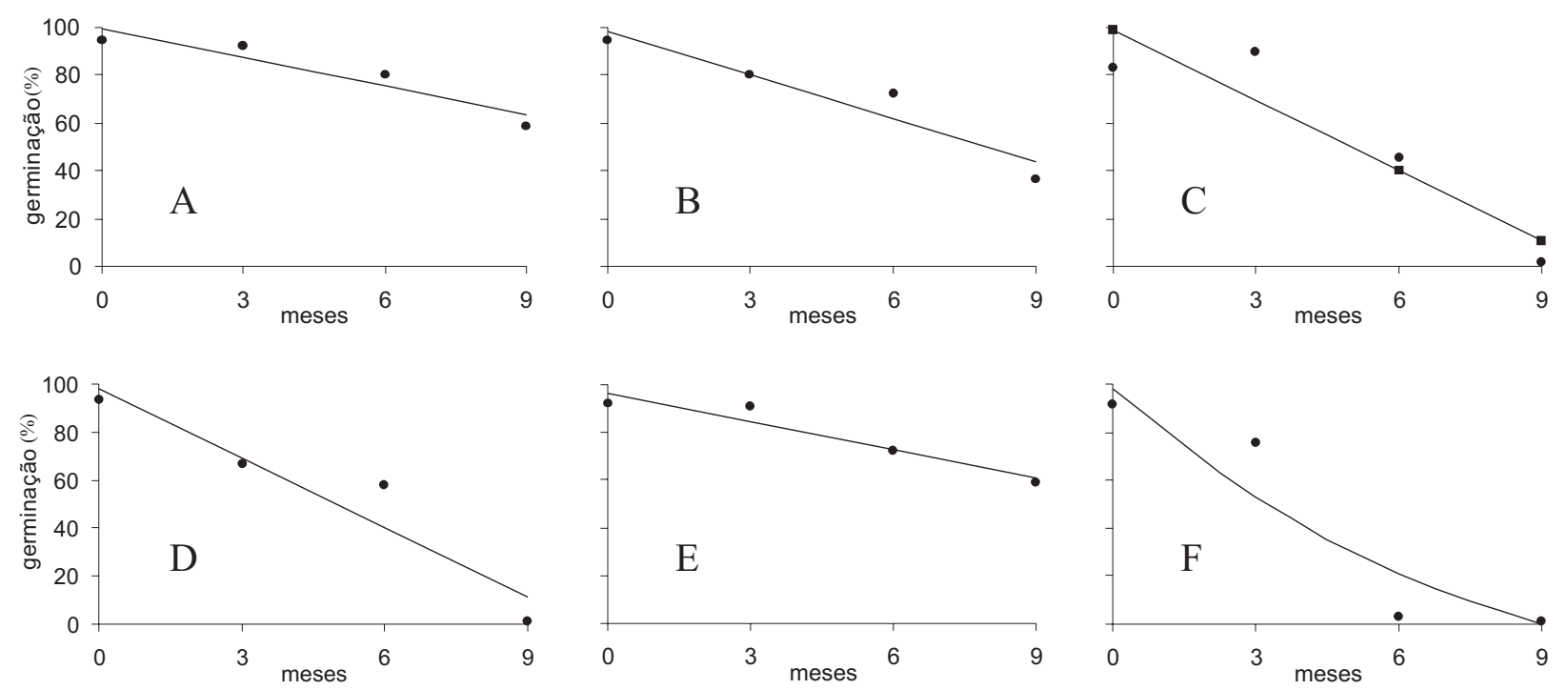

FIGURA 3. Germinação (\%) de sementes de café sem secagem, submetidas à secagem rápida e à secagem lenta e armazenadas em câmara fria e armazém convencional por nove meses. UFLA, Lavras - MG, 2005. 


$$
\begin{array}{lll}
\mathrm{y}_{\mathrm{A}}=99,875-3,958 \mathrm{x} & \mathrm{R}^{2}=91,7 \% & \text { (A) Sem secagem; câmara fria } \\
\mathrm{y}_{\mathrm{B}}=97,075-3,558 \mathrm{x} & \mathrm{R}^{2}=91,0 \% & \text { (B) Sem secagem; convencional } \\
\mathrm{y}_{\mathrm{C}}=100,000-9,750 \mathrm{x} & \mathrm{R}^{2}=84,3 \% & \text { (C) Secagem rápida; câmara fria } \\
\mathrm{y}_{\mathrm{D}}=99,995-9,850 \mathrm{x} & \mathrm{R}^{2}=90,5 \% & \text { (D) Secagem rápida; convencional } \\
\mathrm{y}_{\mathrm{E}}=97,000-3,250 \mathrm{x} & \mathrm{R}^{2}=93,4 \% & \text { (E) Secagem lenta; câmara fria } \\
\mathrm{y}_{\mathrm{F}}=96,200-11,933 & \mathrm{R}^{2}=86,8 \% & \text { (F) Secagem lenta; convencional }
\end{array}
$$
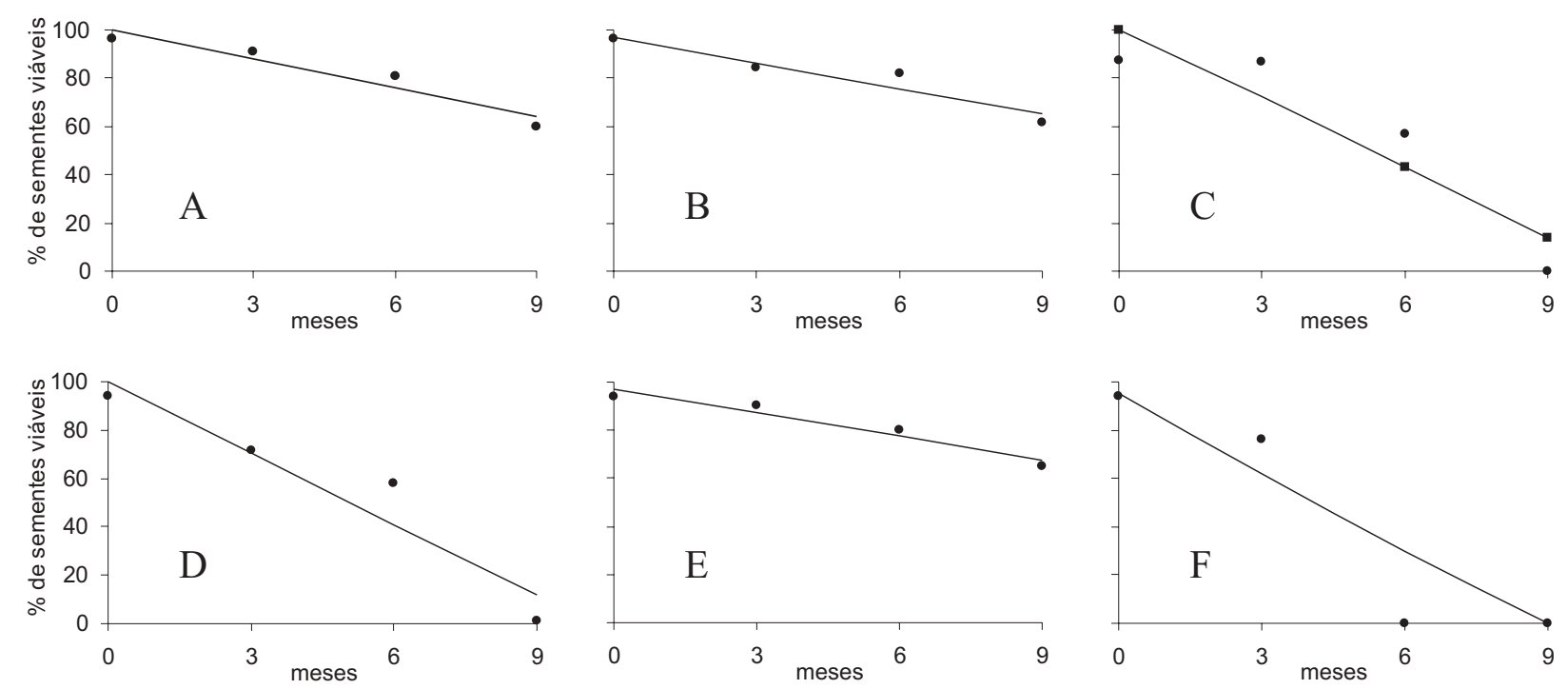

FIGURA 4. Sementes viáveis $(\%)$ pelo teste de tetrazólio, de sementes de café sem secagem, submetidas à secagem rápida e à secagem lenta e armazenadas em câmara fria e armazém convencional por nove meses. UFLA, Lavras - MG, 2005.

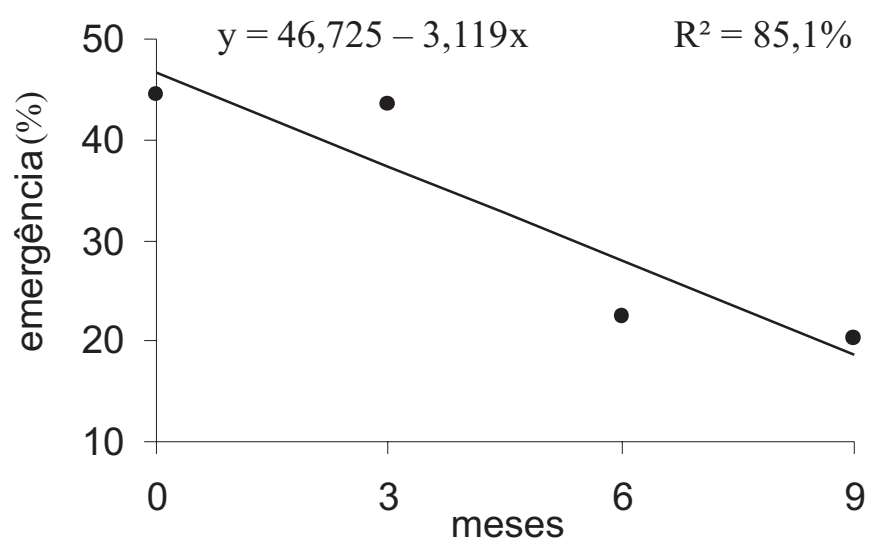

FIGURA 5. Emergência de plântulas (\%), obtidas de sementes de café armazenadas por 9 meses. UFLA, Lavras MG, 2005.

de métodos de secagem associado ao local de armazenamento, nota-se que a porcentagem de emergência das sementes sem secagem foi maior que para aquelas sementes submetidas à secagem rápida, não havendo diferenças significativas quanto à condição de

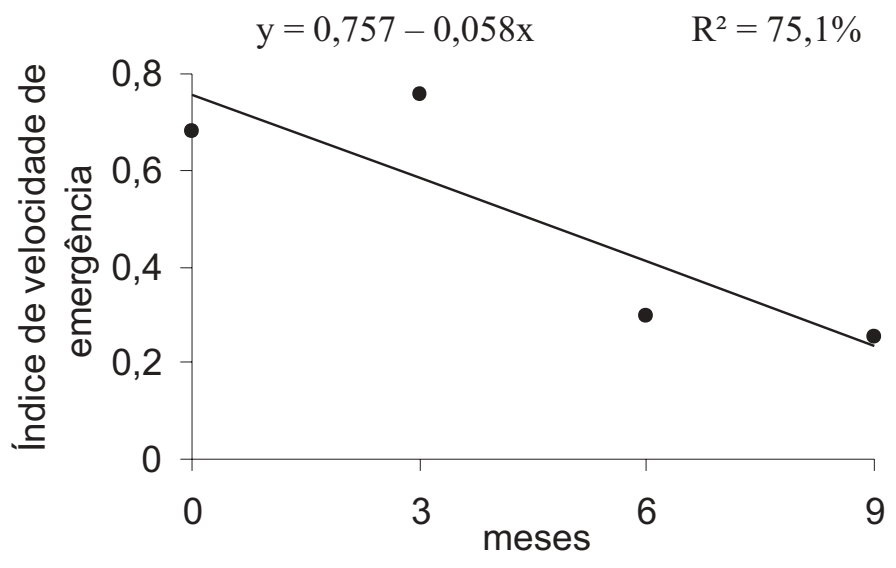

FIGURA 6. Índice de velocidade de emergência de plântulas, obtidas de sementes de café armazenadas por nove meses. UFLA, Lavras - MG, 2005.

armazenamento, o que indica uma maior preservação das sementes de Coffea arabica quando estas não são secadas (Tabela 1). Situação semelhante foi encontrada em estudos realizados por Vossen (1979), Silva e Dias (1985) e Miranda et al. (1993), os quais evidenciaram que, para a conservação 
de sementes de café, são necessários valores relativamente altos de teor de água nas sementes superiores ao do equilíbrio com o ambiente. Entretanto, não houve diferenças significativas entre a porcentagem de emergência das sementes secadas lentamente e armazenadas em câmara fria e as sementes não secadas. Verificou-se ainda que houve significativamente uma maior emergência de plântulas oriundas de sementes secadas lentamente quando estas foram armazenadas em câmara fria, em relação àquelas que foram mantidas em armazém convencional.

Pelos resultados de índice de velocidade de emergência (Tabela 2), observa-se, da mesma forma como para a porcentagem de emergência, que independentemente da época de avaliação, as sementes submetidas à secagem rápida apresentaram uma menor velocidade de emergência em relação àquelas submetidas à secagem lenta e armazenadas em câmara fria e às não secadas. Esse comportamento corrobora relatos de Ellis et al. (1990), os quais demonstram que a principal causa da rápida perda do poder germinativo é a grande sensibilidade dessas sementes à secagem.

TABELA 1. Emergência de plântulas, obtidas de sementes de café sem secagem, submetidas à secagem rápida è̀ secagem lenta e armazenadas em câmara fria e armazém convencional. UFLA, Lavras - MG, 2005.

\begin{tabular}{lcc}
\hline \multirow{2}{*}{ SECAGEM } & \multicolumn{2}{c}{ ARMAZENAMENTO } \\
\cline { 2 - 3 } & Câmara fria & Convencional \\
\hline Sem & $55 \mathrm{aA}$ & $54 \mathrm{aA}$ \\
Rápida & $14 \mathrm{bA}$ & $17 \mathrm{bA}$ \\
Lenta & $42 \mathrm{aA}$ & $14 \mathrm{bB}$ \\
\hline
\end{tabular}

Médias seguidas pela mesma letra maiúscula na linha e minúscula na coluna não diferem estatisticamente entre si, pelo Teste de F e de Tukey, respectivamente, a $5 \%$ de probabilidade.

TABELA 2. Índice de velocidade de emergência de plântulas, obtidas de sementes de café sem secagem, submetidas à secagem rápida e à secagem lenta $\mathrm{e}$ armazenadas em câmara fria e armazém convencional. UFLA, Lavras - MG, 2005.

\begin{tabular}{lcc}
\hline \multirow{2}{*}{ SECAGEM } & \multicolumn{2}{c}{ ARMAZENAMENTO } \\
\cline { 2 - 3 } & Câmara fria & Convencional \\
\hline Sem & $0,820 \mathrm{aA}$ & $0,815 \mathrm{aA}$ \\
Rápida & $0,213 \mathrm{bA}$ & $0,246 \mathrm{bA}$ \\
Lenta & $0,658 \mathrm{aA}$ & $0,230 \mathrm{bB}$ \\
\hline
\end{tabular}

Médias seguidas pela mesma letra, maiúscula na linha e minúscula na coluna, não diferem entre si, pelo Teste de F e de Tukey, respectivamente, a 5\% de probabilidade.

\section{CONCLUSÕES}

A secagem rápida prejudica o vigor e a viabilidade das sementes de café, independentemente do local de armazenamento.

Em condições de câmara fria é possível armazenar sementes sem secagem ou secadas lentamente, por nove meses.

Independentemente do tipo de secagem, o vigor das sementes é afetado no armazenamento em condições de armazém convencional.

\section{REFERÊNCIAS}

ANDREOLI, D.M.C. Qualidade fisiológica de sementes de café (Coffea canephora cv. Guarani) armazenadas com diferentes graus de umidade em dois tipos de embalagem após secagem natural e artificial. 1992. 87f. Dissertação (Mestrado em PréProcessamento) - Universidade de Campinas, Campinas, 1992.

BRASIL. Ministério da Agricultura. Regras para análise de sementes. Brasília:SNDA/DNDV/CLAV, 1992.365p.

CARVALHO, J.A. de. Conservação de sementes de citros e testes rápidos para a avaliação da qualidade fisiológica. 2001. 140f. Tese (Doutorado em Fitotecnia) - Universidade Federal de Lavras, Lavras, 2001.

CARVAlho, N.M.; NAKAGAWA, J. Sementes: ciência, tecnologia e produção. Jaboticabal: FUNEP, 2000. 588p.

COUTURON, E. Mantenimiento de la viabilidad de las semillas de cafetos por el control de su contenido en agua y de la temperatura de almacenamiento. Cafe Cacao The, Paris, v.24, n.1, p.27-32, 1980.

ELLIS, R.H.; HONG, T.D.; ROBERTS, E.H. An intermediate category of seed storage behaviour?: I. Coffee. Journal of Experimental Botany, Oxford, v.41, n.230, p.1167-1174, 1990.

GENTIL, D.F. de O.; SILVA, W.R. da; MIRANDA, D.M. de. Grau de umidade e temperatura na conservação de sementes de café. Bragantia, Campinas, v.60, n.1, p.53-64, 2001.

KING, M.W.; ROBERTS. E.H. The storage of recalcitrant seeds: achievements and possible approaches. Rome: International Board for Plant Genetic Resources, 1979. 96p.

INSTITUTO MINEIRO DE AGROPECUÁRIA. Normas e padrões para a produção de sementes básicas e fiscalizadas de café. Anexo I da Portaria $\mathrm{n}^{\circ}$ 388, de 22 de maio de 2000.

MAGUIRRE, J.D. Speed of germination aid in selection and evoluation for seedling and vigour. Crop Science, Madison, v.2, n.2, p.176-177, 1962.

MIGLIORANZA, E. Conservação de sementes de café (Coffea arabica L. cv. Catuaí), com diferentes teores de umidade, armazenadas em embalagens hermeticamente fechadas. 1982. 60f. Dissertação (Mestrado em Fitotecnia) - Escola Superior de Agricultura Luiz de Queiroz, Piracicaba, 1982.

MIRANDA, J.M.; VALIAS, E.P. Estudo sobre conservação da 
viabilidade de sementes de café. In: CONGRESSO BRASILEIRO DE PESQUISAS CAFEEIRAS, 1,. 1984, Londrina. Resumos... Rio de Janeiro: Ministério da Indústria e do Comércio IBC, 1984. p.160161.

MIRANDA, J.M.; CARVALHO M.M. de; CARVALHO, M.L.M. de; VIEIRA, M. das G.G.C. Estudos de alguns fatores que influenciam a duração da viabilidade de sementes de café. Revista Brasileira de Sementes, Brasília, v.15, n.2, p.215-220, 1993.

MINOR, H.C.; PASCHAL, E.H. Variation in storability of soybeans under simulated tropical condition. Seed Science and Technology, Zürich, v.10, n.1, p.131-139, 1982.

POPINIGIS, F. Fisiologia da semente. 2.ed. Brasília, DF: AGIPLAN, 1985.289p.

ROBERTS. E.H. Storage environment and the control of viability. In: ROBERTS, E.H. Viability of seeds. London: Syracuse University Press, 1972. p.14-58.

SILVA, W.R.; DIAS, M.C.L. de L. Interferência do teor de umidade das sementes de café na manutenção de sua qualidade fisiológica.
Pesquisa Agropecuária Brasileira, Brasília, v.20, n.5, p.551-560, 1985.

TeKRONY, D.M.; EGLI, D.B; WHITE, G.M. Seed production and technology. In: WILCOX, J.R. (Ed.). Soybeans: improvement, production and uses 1. Madison: American Society of Agronomy, 1987. p.295-353.

VALIO, I.F.M. Germination of coffee seeds (Coffea arabica L. cv. Mundo Novo). Journal of Experimental Botany, London, v.27, n.100, p.983-991, 1976.

VASCONCELOS, L.M.; GROTH, D.; RAZERA, L.F. Efeito de processos de secagem, diferentes graus de umidade e tipos de embalagens na conservação de sementes de café (Coffea arabica L. cv. Catuaí Vermelho). Revista Brasileira de Sementes, Brasília, v.14, n.2, p.181-188, 1992.

VOSSEN, H.A,M. van der. Methods of preserving the viability of coffee seed in storage. Seed Science and Technology, Zürich, v.7, n.1, p.65-74, 1979. 